\title{
Sistem Informasi Penawaran Proyek Pembangunan Pada CV. Nur Fiqri Pontianak
}

\author{
Deasy Purwaningtias ${ }^{[1]}$, Deni Risdiansyah ${ }^{[2]}$

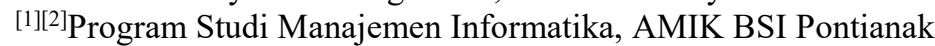 \\ E-mail : deasy.dwg@bsi.ac.id ${ }^{[1]}$, deni.drx@bsi.ac.id ${ }^{[2]}$
}

\begin{abstract}
ABSTRAK
Abstrak-Membuat surat penawaran adalah hal yang wajib dilakukan oleh kontraktor untuk mendapatkan proyek yang mereka inginkan tetapi karena banyaknya persaingan maka para kontraktor bersaing untuk membuat surat-surat penawaran yang sebaikbaiknya agar pihak penawaran lebih tertarik kepada penawar itu sendiri. Tetapi karena media aplikasi yang digunakan sekarang masih di anggap belum cukup fleksibel maka terkadang tidak sedikit kendala dalam pembuatan surat yang dilakukan selama ini. Oleh karena itu dalam penelitian yang dilakukan, diharapkan dapat menghasilkan suatu kayra yaitu sebuah aplikasi yang diharapkan dapat membantu bagian administrasi maupun staf pada CV. NUR FIQRI dalam pembuatan surat-surat penawaran yang baik sehingga dapat membantu dalam pekerjaan.
\end{abstract}

Kata Kunci : Surat Penawaran, Aplikasi, Perusahaan

Abstract-Creating a letter of offer is something that the contractor must do to get the project they want but because of the competition, the contractors compete to make the best possible bidding letters to make the bidder more interested in the bidder itself. But because the media applications that are used now are still not flexible enough then sometimes not a few obstacles in the making of letters done so far. Therefore, in research conducted, is expected to produce a kayra is an application that is expected to assist the administration and staff at CV. NUR FIQRI in the making of good offer letters so as to assist in the work.

Index Terms: Offer Letter, Application, Company 


\section{PENDAHULUAN}

Kepadatan penduduk di wilayah Kalimantan Barat semakin lama semakin meningkat. Peningkatan jumlah populasi penduduk di wilayah Kalimantan Barat membuat banyaknya peluang dalam hal pembangunanpembangunan di daerah tersebut. Mulai dari pembuatan maupun perbaikan jalan, pembangunan gedung-gedung perkantoran, hingga pembangunan perumahan dan ruko. Semakin banyaknya kontraktor yang ikut serta maka semakin banyaknya persaingan dalam mendapatkan peluang tersebut. Untuk bisa mendapatkan proyek yang tersedia maka para kontraktor saling bersaing untuk membuat surat penawaran yang semenarik mungkin.

CV. Nur Fiqri adalah salah satu perusahaan yang bergerak dalam bidang kontraktor. Salah tugas CV. Nur Fiqri adalah membuat surat penawaran untuk panitia penawar pekerjaan. Tetapi karena pembuatannya yang masih mengandalkan text editor mocrosoft office membuat pekerjaan CV. Nur Fiqri sedikit kurang efektif.

Adapun permasalahan yang dihadapi antara lain :

a. Untuk setiap pengerjaan sebuah surat penawaran mereka harus membuat sebuah file untuk surat tersebut, sehingga banyak tempat file yang di simpan di dalam PC/Laptop mereka.

b. Pencarian data yang memakan waktu.

c. Terkadang ada surat yang tidak ditemukan karena tempat penyimpanan yang terlupakan.

Tujuan dari penulisan ini adalah dapat memberikan alternatif solusi pemecahan masalah yang dihadapai oleh kontraktor dalam pembuatan surat-surat penawaran.

\section{TINJAUAN PUSTAKA}

\subsection{Sistem}

Menurut Pratama (2014:7)

mengemukakan bahwa "Sistem didefinisikan sebagai sekumpulan prosedur yang saling berkaitan dan saling terhubung untuk melakukan suatu tugas bersama-sama".

Definisi menurut Fatta (2007:3) yaitu "Sistem dapat diartikan sebagai suatu kumpulan atau himpunan dari unsur atau variabel-variabel yang saling terorganisasi, saling berinteraksi, dan saling bergantung sama lain".

\subsection{Informasi}

Menurut Pratama (2014:9) yaitu "Informasi merupakan hasil pengolahan data dari satu atau berbagai sumber, yang kemudian diolah, sehingga memberikan nilai, arti, dan manfaat"

Menurut Davis didalam Fatta (2007:9) mengemukakan bahwa "Informasi adalah data yang telah diolah menjadi sebuah bentuk yang berarti bagi penerimanya dan bermanfaat dalam pengambilan keputusan saat ini atau mendatang".

\subsection{Sistem Informasi}

Menurut Pratama (2014:10) bahwa "Sistem informasi merupakan gabungan dari empat bagian utama. Keempat bagian utama tersebut mencakup perangkat lunak (software), perangkat keras (hardware), infrastruktur, dan Sumber Daya Manusia (SDM) yang terlatih. Keempat bagian utama ini saling berkaitan untuk menciptakan sebuah sistem yang dapat mengelola data menjadi informasi yang bermanfaat".

Sistem Informasi didefinisikan sebagai suatu alat untuk menyajikan informasi dengan cara sedemikian rupa 
sehingga bermanfaat bagi penerimanya menurut Kertahadi didalam Fatta (2007:9) dan terditi dari beberapa komponen sebagai berikut :

A. Perangkat keras, yaitu komponen untuk melengkapi kegiatan memasukkan data, memproses data, dan keluaran data.

B. Perangkat lunak, yaitu program dan intruksi yang diberikan kekomputer.

C. Database, yaitu kumpulan data dan informasi yang diorganisasikan sedemikian rupa sehingga mudah diakses pengguna sistem informasi.

D. Telekomunikasi, yaitu komunikasi yang menghubungkan antara pengguna sistem dengan sistem komputer secara bersama-sama kedalam suatu jaringan kerja yang efektif.

E. Manusia, yaitu personel dari sistem informasi, meliputi manajer, analis, programer, dan operator, serta bertanggung jawab terhadap perawatan sistem.

\subsection{Visual Basic}

Menurut Komputer (2009:2) mengemukakan bahwa "Visual basic adalah bahasa pemograman tingkat tinggi yang sudah sangat terkenal, dimulai dengan BASIC yang terdapat pada komputer angkatan tua, seperti AT286".

\subsection{MySQL}

Menurut Faisal (2011:126) bahwa "MySQL merupakan database server yang bersifat multiuser dan multithreaded. SQL adalah bahasa database standar yang memudahkan penyimpanan, pengubahan dan akses informasi. Pada MySQL dikenal istilah database dan tabel. Tabel adalah sebuah struktur data dua dimensi yang terdiri dari baris-baris record dan kolom."

Menurut Madcoms (2008:52) yaitu "MySQL merupakan salah satu software database (basis data) open source yang dikembangkan sebuah komunitas bernama MySQL AB dengan tujuan membantu user untuk menyimpan data dalam tabel-tabel".

Tabel terdiri atas field atau kolom yang mengelompokan data-data berdasarkan kategori tertentu, seperti nama, alamat, nomor telepon, dan sebagainya. Bagian lain dari tabel adalah record atau baris yang berisikan data yang sebenarnya.

MySQL maupun software database yang lain dapat hubungkan oleh aplikasi-aplikasi yang berbeda, baik dari sisi tujuan maupun dari sisi bahasa pemrograman yang digunakan oleh masing-masing aplikasi yang bersangkutan. Ada empat instruksi dasar yang digunakan dalam sql (structured query language), yaitu :

A. Select

Digunakan untuk menampilan data yang telah ada atua tersimpan.

B. Insert

Digunakan untuk menambahkan data yang baru kedalam database.

C. Update

Digunakan untuk mengubah data yang telah disimpan sebelumnya pada database.

D. Delete

Digunakan untuk menghapus data yang telah ada pada database.

\subsection{Hierarchy Input Process Output (HIPO)}

Merupakan alat dokumentasi program. Akan tetapi sekarang, banyak digunakan sebagai alat desain dan teknik 
dokumentasi dalam siklus pengembangan sistem yang berbasis pada fungsi, yaitu tiap-tiap modul di dalam sistem digambarkan oleh fungsi utamanya. Menurut Fatta (2007:147) HIPO merupakan teknik untuk mendokumentasikan pengembangan suatu sistem yang dikembangkan oleh IBM.

HIPO dapat digunakan sebagai alat pengembangan sistem dan teknik dokumentasi program. Penggunaannya mempunyai beberapa sasaran, yaitu:
A. Untuk menyediakan suatu struktur guna memahami fungsi-fungsi dari sistem.
B. Untuk lebih menekankan fungsi- fungsi yang harus diselesaikan oleh program.
C. Untuk menyediakan penjelasan yang jelas dari input yang harus digunakan dan output yang dihasilkan.

\subsection{LRS}

Model relasional secara formal diperkenalkan oleh Dr. E. F. Codd pada tahun 1970 dan berkembang saat itu melalui serangkaian tulisan. Pada model relasional, suatu basis data merupakan suatu kumpulan tabel relational. Menurut Simarmata (2007:156) suatu tabel relasional adalah suatu file flat yang terdiri atas sekumpulan kolom dan sejumlah baris yang tak dikenal. Sedangkan suatu relationship adalah suatu keterkaitan antara dua tabel atau lebih yang hubungannya dinyatakan dengan kunci utama dan kunci tamu.

Kunci merupakan sebuah kombinasi dari satu kolom atau lebih yang berada didalam suatu tabel yang secara unik mendefinisikan baris dalam tabel. Menurut Simarmata (2007:162) ada empat sifat yang diinginkan pada kunci :
A. Familiarity: Nilai-nilai kunci harus berarti bagi pengguna.
B. Stability: Nilai-nilai kunci tidak harus bisa diubah.
C. Minimality: Kolom harus tercakup di dalam kunci jika penting untuk keunikan.
D. Simpicity: Pendek, kunci yang sederhana lebih baik daripada panjang. Secara konseptual, kunci bersifat kompleks.

\subsection{SDLC}

Menurut Rosa dan Shalahuddin (2013:28) mengatakan bahwa "Model Waterfall adalah Model SDLC air terjun (waterfall) sering juga disebut model sekuensial linier (sequential linear) atau alur hidup klasik (classic life cycle). Model air terjun menyediakan pendekatan alur hidup perangkat lunak secara sekuensial atau terurut dimulai dari analisa, desain, pengkodean, pengujian dan tahap pendukung (support)".

\section{METODOLOGI}

\subsection{Pengumpulan Data Primer}

Pengumpulan data dilakukan dengan melakukan wawancara langsung kepada Direktur dan beberapa karyawan CV. Nur Fiqri Pontianak.

\subsection{Pengumpulan Data Sekunder \\ Mengumpulkan data dengan cara membaca dan mempelajari buku-buku, makalah-makalah, artikel-artikel dan bahan-bahan dari internet yang sesuai dengan topik yang sedang dibahas.}

\subsection{Pengembangan Perangkat Lunak \\ Metode pengembangan perangkat lunak yang digunakan adalah metode}


Waterfall. Sebuah pendekatan kepada perkembangan perangkat lunak yang sistematik dan sekuensial mulai dari tingkat dan kemajuan sistem pada analisis, desain, kode, pengujian, dan pemeliharaan. Terdiri dari beberapa tahapan, yaitu: tahap analisis, perancangan, pengkodean, dan pengujian

\section{HASIL DAN PEMBAHASAN}

CV. NUR FIQRI didirikan di Pontianak pada tanggal 3 Maret 2008 dengan Akta Nomor 12 dihadapan notaris Eddy Dwi Pribadi, SH di Jalan Husin No. 3 Pontianak. Tujuan utama pendirian perusahaan ini adalah agar dapat ikut berpartisipasi dan membantu Pemerintah Republik Indonesia di dalam melaksanakan Pembangunan disegala bidang jasa konstruksi.

Dengan adanya struktur organisasi maka tidak akan timbul kesimpang siuran dalam melaksanakan tugas-tugas yang diberikan oleh pemimpin perusahaan. Dalam hal ini strutur organisasi yang dipakai pada CV. NUR FIQRI adalah sebagai berikut :

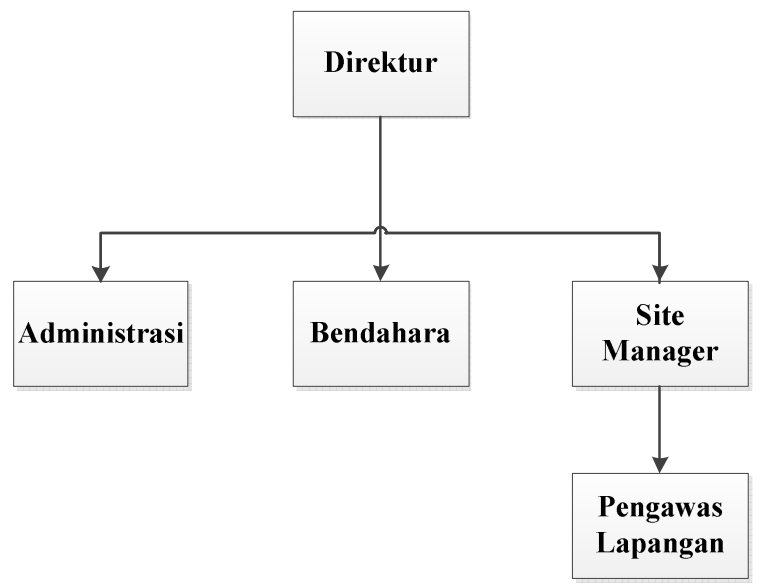

Sumber: CV. NUR FIQRI

Gambar 1. Struktur Organisasi CV. NUR FIQRI
Dari kebutuhan yang ada maka didapatkan analisa kebutuhan sistem sebagai berikut :

a. Proses login

Pengguna aplikasi wajib memasukkan username dan password sebagai bukti bahwa pengguna tersebut memiliki hak akses pada aplikasi yang dibuat.

b. Proses memasukkan data-data perusahaan

Sebelum pembuatan surat, pengguna wajib memasukkan data-data perusahaan yang sifatnya berkesinambungan atau sekali untuk selamanya hingga ada proses perubahan data yang ditentukan waktu perubahannya maupun tidak.

c. Proses memasukkan data-data pekerjaan baru

Pengguna cukup memasukkan datadata pekerjaan pada form yang ditentukan, form ini cukup sederhana dan diharapkan dapat mengefisiensikan waktu pengerjaan surat.

d. Proses mencetak surat penawaran

Setelah semua proses di atas selesai maka pengguna cukup memilih surat mana yang akan di cetak. Setelah memilih maka selanjutnya pengguna mengklik tombol cetak yang telah di sediakan pada aplikasi.

e. Proses menambahkan pengguna Untuk pengguna yang memiliki hak akses khusus / administrator dapat menambah atau mengungari daftar pengguna yang boleh mengakses aplikasi demi keamanan data.

\subsection{Perancangan Aplikasi}

Beberapa rancangan antarmuka pada aplikasi antara lain sebagai berikut 
A. Saat program pertama kali dijalankan maka akan muncul tampilan Login, jika berhasil login maka akan muncul halaman utama yang berisikan menu Data Perusahaan, Pembuatan Surat, Modal Pekerjaan, Persentase Pekerjaan, Cetak Surat Penawaran, Tambah Admin dan Keluar.

B. Menu Data Perusahaan berfungsi untuk menambah, mengubah dan menghapus data-data SITU, SIUP, Pekerjaan, Persinalia, Perusahaan, Komanditer, Akta, IUJK, Pajak dan SBU. Data-data tersebut cukup disikan sekali saja untuk dapat digunakan saat pembuatan surat.

C. Menu Pembuatan Surat untuk mengelola data surat penawaran yang baru maupun melihat daftar surat penawaran sebelumnya.

D. Model Pekerjaan digunakan untuk mendata asal dana yang didapat selama pekerjaan itu berlangsung.

E. Persentase Pekerjaan digunakan untuk memantau progres pekerjaan yang sedang berlangsung.

F. Menu Cetak Surat Penawaran digunakan untuk mencetak ulang surat penawaran yang sudah pernah dibuat.

G. Menu Tambah Admin Baru, digunakan untuk mengelola siapa saja yang bisa mengakses aplikasi ini.

H. Menu Keluar digunakan untuk mengakhiri aplikasi. 


\subsection{Hierarchy Input Process Output (HIPO)}

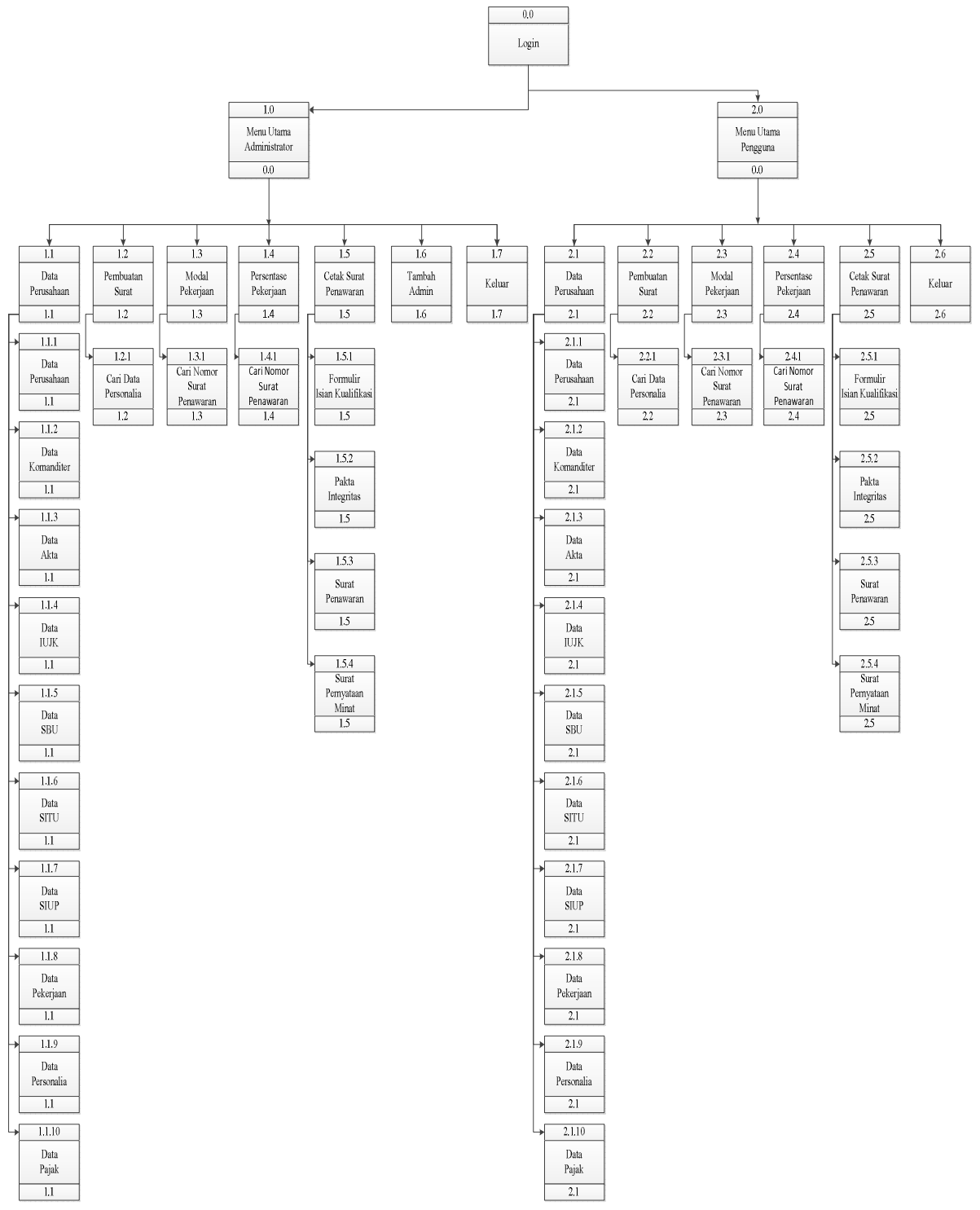

Sumber : Hasil Penelitian

Gambar 2. HIPO 


\subsection{Database}

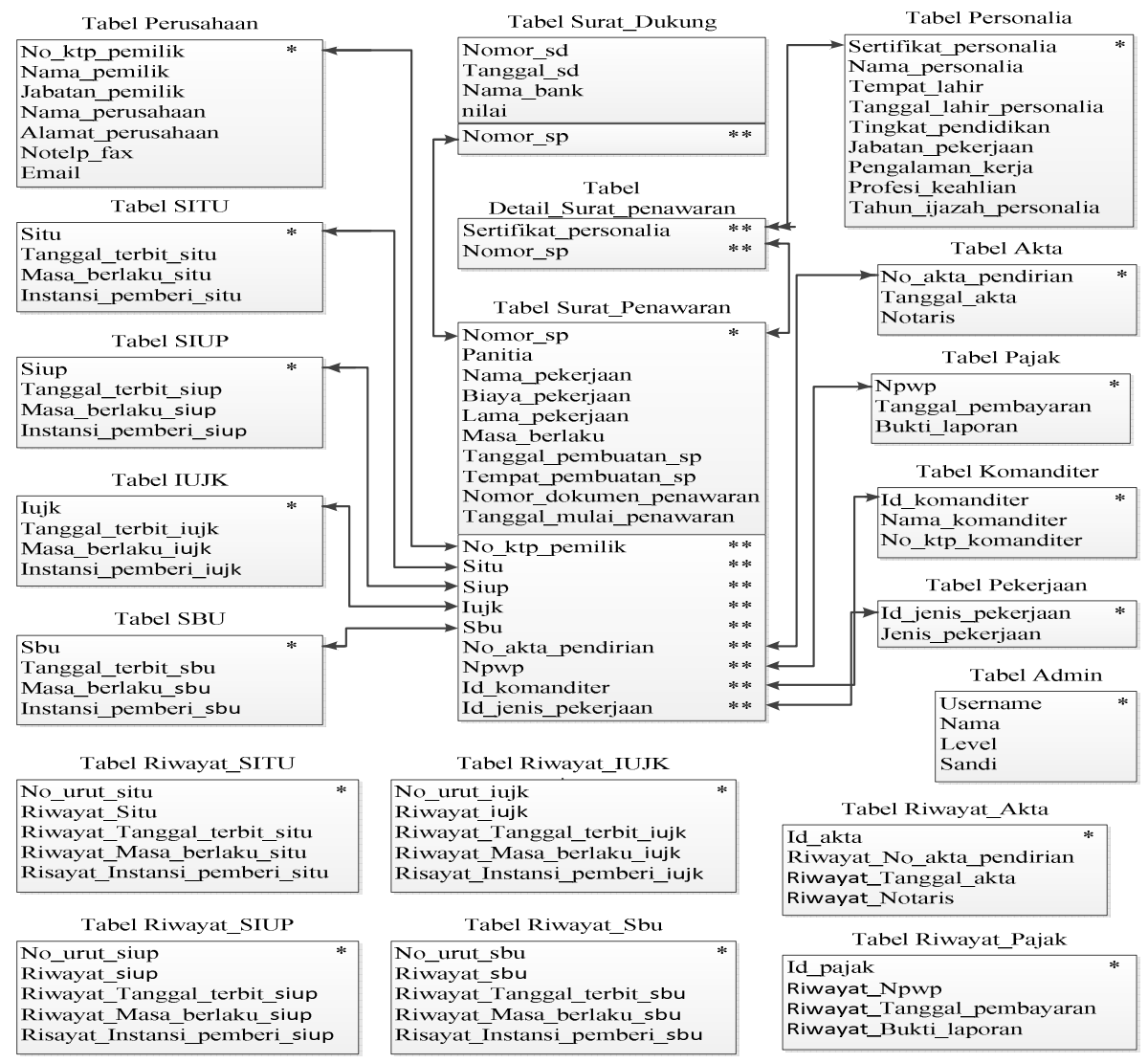

Sumber : Hasil Penelitian

\section{Gambar 3. Logical Relational Strukture (LRS)}

\subsection{Desain Interface}

A. Tampilan Masuk

Tampilan ini digunakan untuk verifikasi siapa saja yang berhak masuk kedalam sistem. Tentu saja data-data admin tersebut telah disimpan terlebih dahulu sebelum kita mencoba masuk.

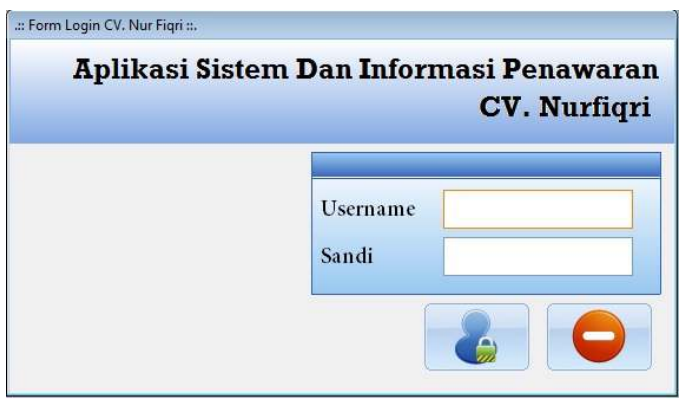

Gambar 4. Tampilan Masuk

\section{B. Tampilan Menu Utama}

Ini adalah tampilan kedua pada sistem setelah kita berhasil masuk. Disini terdapat beberapa menu diantaranya Data Perusahaan, Pembuatan Surat, Modal Pekerjaan, Persentase Pekerjaan, Cetak Surat Penawaran, Tambah Admin dan Tombol Keluar.

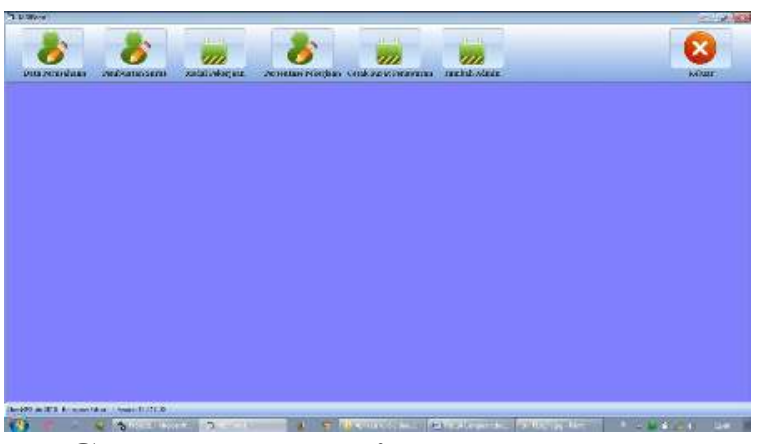

Gambar 5. Tampilan Menu Utama

C. Tampilan Data Perusahaan

Menu ini berfungsi untuk mengelola data-data yang berhubungan dengan perusahaan seperti SITU, SIUP, Pekerja, Personalia, Komanditer, Akta, IUJK, SBU dan Pajak. Data-data tersebut cukup dimasukkan sekali saja dan selanjutnya otomatis terpanggil ketika ingin mengelola surat yang baru akan dibuat. 


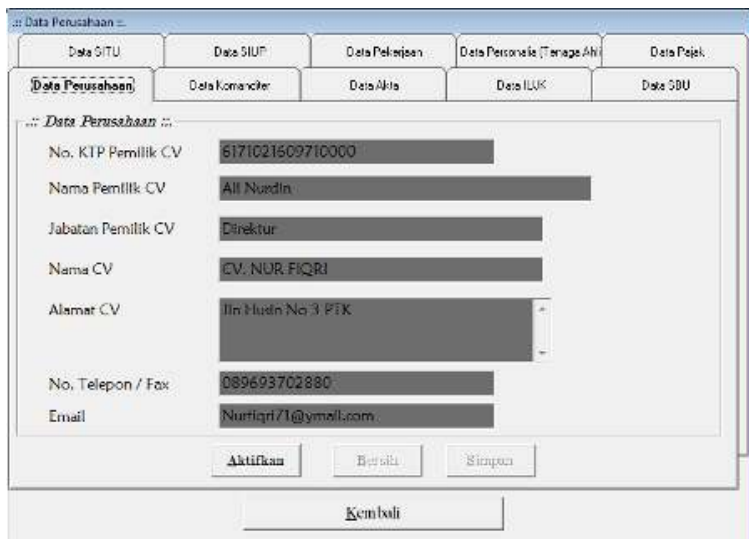

Gambar 6. Tampilan Data Perusahaan

D. Tampilan Pembuatan Surat Penawaran Ini adalah fungsi utama pada aplikasi ini. Pembuatan surat penawaran merupakan gabungan dari beberapa data perusahaan yang sebelumnya telah tersimpan dan selanjutnya data-data tersebut akan dikelola dengan data pendukung lainnya sehingga terbentuknya Surat Penawaran untuk perusahaan tersebut.

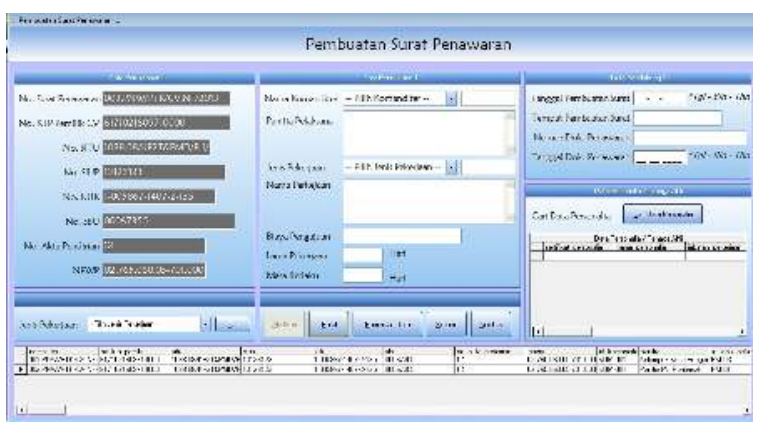

\section{Gambar 7. Tampilan Pembuatan Surat} Penawaran

E. Tampilan Modal Kerja Perusahaan

Tampilan ini sebagai media informasi dana yang didapat dan nominal modal awal yang dipinjamkan oleh pihak Bank.

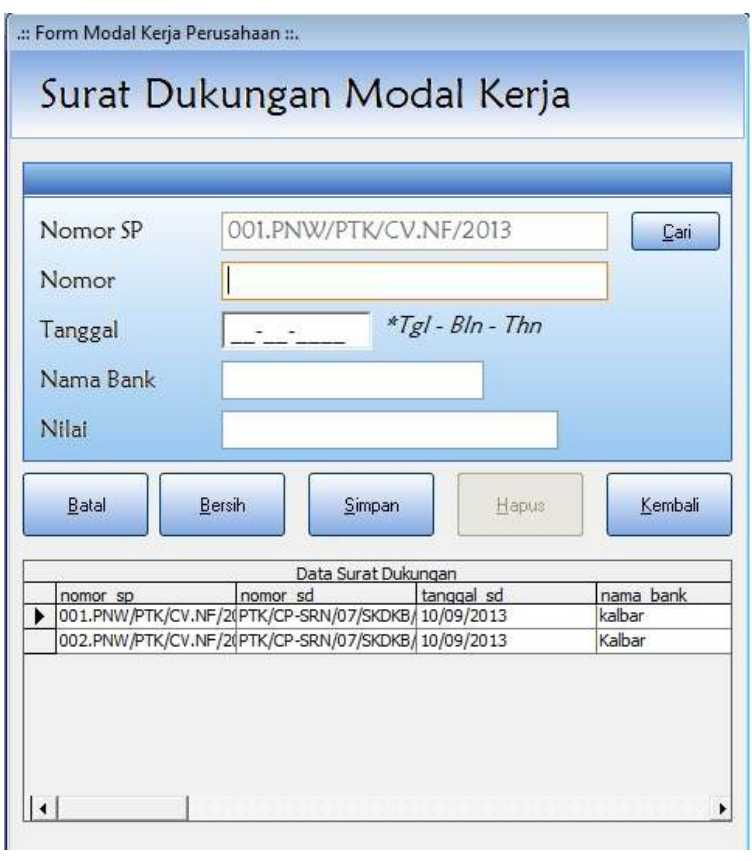

\section{Gambar 8. Tampilan Modal Kerja Perusahaan}

\section{F. Tampilan Persentase Pekerjaan}

Jika pekerjaan sudah berhasil didapat, maka menu ini berfungsi untuk memantau progres pekerjaan dari mulai hingga selesai dengan hitungan perkiraan.

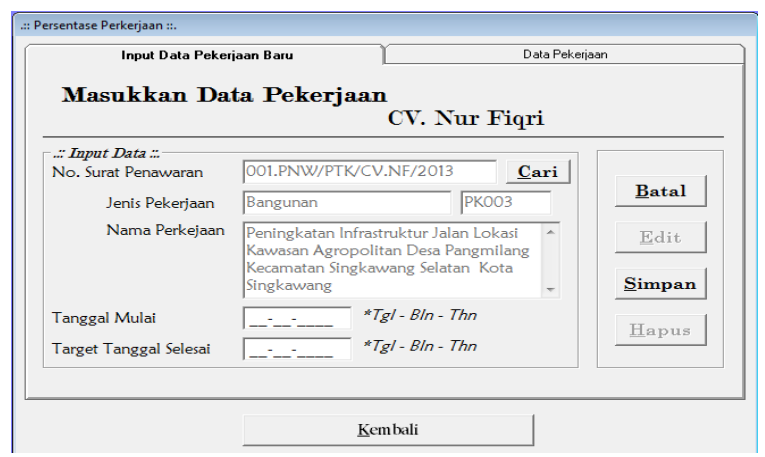

\section{Gambar 9. Tampilan Persentase Pekerjaan}

\section{G. Tampilan Cetak Surat Penawaran}

Menu ini berisikan riwayat pembuatan surat penawaran sebelumnya. Jika butuh mencetak ulang surat yang pernah dibuat maka pengguna cukup akses menu ini dan mencari kode surat yang pernah dibuat.

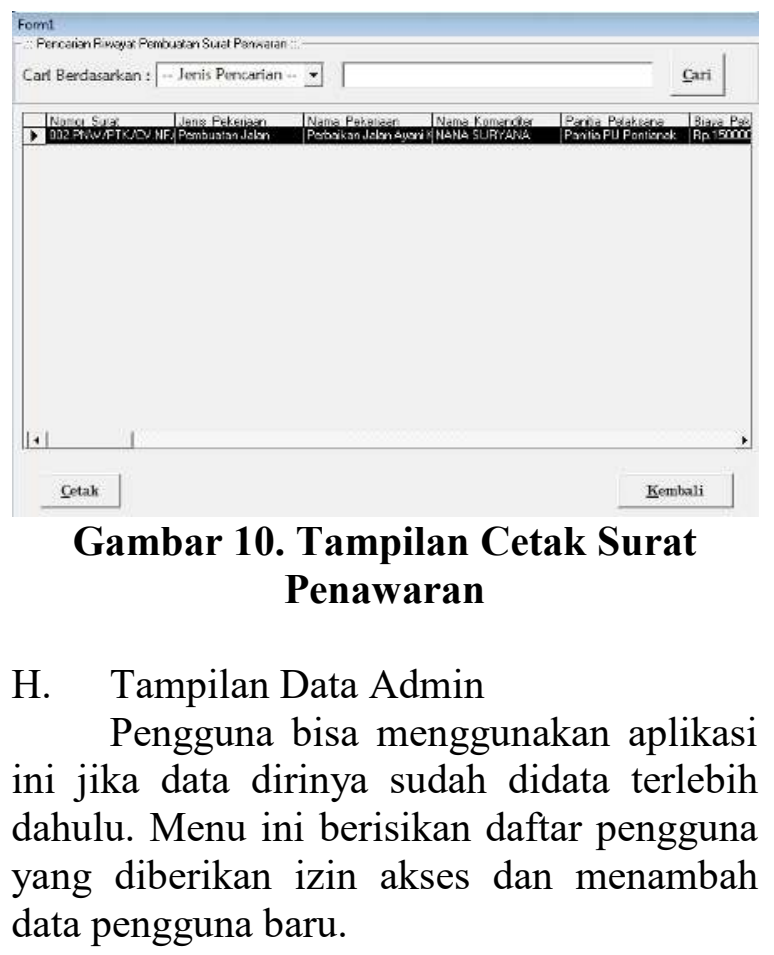




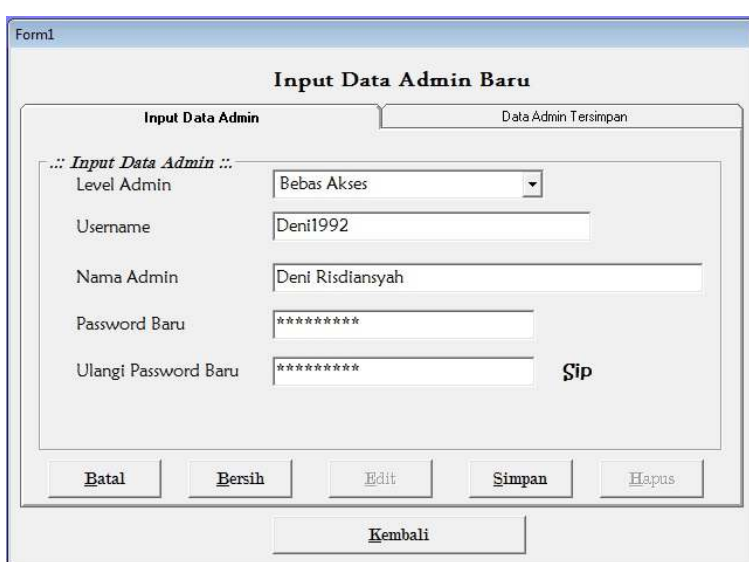

Gambar 11. Tampilan Tambah Admin

\section{KESIMPULAN}

Berdasarkan hasil penelitian yang telah dilakukan dapat diambil beberapa kesimpulan diantaranya:

a. Dalam mengisi data-data perusahaan maka bagian administrasi cukup menginputkan data-data tersebut satu kali saja hingga ada perubahan data, setelah itu bagian administrasi cukup memasukkan data-data pendukung untuk surat-surat yang akan di cetak sehingga bagian administrasi tidak perlu membuat surat dari awal lagi.

b. Data-data surat akan tersimpan di dalam satu database sehingga bagian administrasi tidak perlu menyimpan berkas surat yang banyak karena akan sulit dalam pencarian arsip data.

c. Dalam keamanan aplikasi maka penulis telah menyiapkan fungsi keamanan berupa login sehingga bagi orang-orang yang tidak memiliki hak untuk mengakses aplikasi ini tidak dapat membukanya.

\section{REFERENSI}

[1] Fatta, Hanif Al. 2007. Analisis \& Perancangan Sistem Informasi untuk Keunggulan Bersaing Perusahaan dan Organisasi Modern. Yogyakarta: CV. Andi Offset.

[2] Komputer, Wahana. 2009. Visual Basic 2008. Yogyakarta : CV. Andi Offset.

[3] Madcoms. 2008. Teknik Mudah Membangun Website dengan HTML, PHP, dan MySQL. Yogyakarta: CV Andi Offset.

[4] Pratama, I Putu Agus Eka. 2014. Sistem Informasi dan Implementasinya. Bandung : Informatika.

[5] Simarmata, Janner. 2007. Perancangan Basis data. Yogyakarta : CV. Andi Offset. 